\title{
DETERMINATION OF TWO COLOR AGENTS IN HARD BOILED CANDY BY LASER-BASED PHOTOACOUSTIC SPECTROSCOPY AND COLORIMETRY
}

\author{
Mihály Kovács ${ }^{1}$, Ottó Dóka ${ }^{1 *}$, David Richfield ${ }^{2}$ \\ ${ }^{1}$ Department of Physics and Chemistry. Faculty of Mechanical Engineering, Informatics and Electrical \\ Engineering. Széchenyi István University. H-9026 Györ, Egyetem sq. 1., Hungary \\ ${ }^{2}$ Südzucker AG Zentralabteilung Forschung, Entwicklung, Services (ZAFES), Wormser Str. 11, D-67283 \\ Obrigheim, Germany \\ *doka.otto@sze.hu
}

https://doi.org/10.34302/2019.11.4.11

\begin{tabular}{|c|c|}
\hline Article history: & \multirow{5}{*}{$\begin{array}{l}\text { ABSTRACT } \\
\text { Determination of color agents was performed by laser-based photoacoustic } \\
\text { spectroscopy (LPAS) and colorimetry in hard boiled candies containing two } \\
\text { different colorants (anthocyanin and beta carotene). LPAS and colorimetry } \\
\text { are fast and direct methods which do not require any chemicals or } \\
\text { complicated sample preparation such as extraction. Both LPAS and } \\
\text { colorimetry were shown to be suitable for quick determination of } \\
\text { anthocyanin and beta carotene content in hard boiled candies. The } \\
\text { determination of anthocyanin content in colored hard-boiled candies is } \\
\text { possible by LPAS at } 532 \mathrm{~nm} \text { or by colorimetry using } \triangle \mathrm{E}^{*} \text {, while the beta } \\
\text { carotene content can be measured by LPAS at } 473 \mathrm{~nm} \text { or by colorimetry } \\
\text { using the Hue color index. }\end{array}$} \\
\hline & \\
\hline Accepted: & \\
\hline 29 November 2019 & \\
\hline $\begin{array}{l}\text { Keywords: } \\
\text { Anthocyanin (E163); } \\
\text { Beta carotene (E160a); } \\
\text { Colored hard-boiled candy; } \\
\text { Laser-based photoacoustic } \\
\text { spectroscopy; } \\
\text { Colorimetry. }\end{array}$ & \\
\hline
\end{tabular}

\section{Introduction}

Color is a key product attribute of foods and food supplements, and the colorants that have been approved by regulatory authorities for use in foods cover a wide range of hues. These colorants can be synthetic or natural in origin, with the natural colors including pure dyes and pigments, extracts, and coloring foodstuffs. The quality and dosage of food dyes are strictly regulated.

Many food producers have started to substitute artificial colorants with natural alternatives to achieve "clean label" in alignment with consumer preferences, due to concerns about possible health effects of artificial colorants (Burrows, 2009; Sloan, 2011; Shahid et al., 2013; Cassiday, 2017; Bateman et al., 2004; Mccann et al., 2007).

The consumption of natural colorants has increased by $10-15 \%$ annually in recent years, a trend that is expected to continue (Cortez et al., 2017).

The most important natural food colorants contain colored molecules from the chemical families of anthocyanins, carotenoids, chlorophylls, and betalains (Rodriguez-Amaya, 2016).

The anthocyanins (E163) form the largest group of water-soluble natural dyes, with more than 600 known (Prior and $\mathrm{Wu}, 2012$ ). Their molecular structure changes reversibly depending on $\mathrm{pH}$, due to multiple protonation reactions (Torskangerpoll and Andersen, 2005; Wrolstad and Culver, 2012; Rakic et al., 2015) which lead to color changes. Depending on their chemical structure, anthocyanins can be pink, red, violet, blue or cyan (Carocho and Morales, 2015; Cui et al., 2016). They can also undergo irreversible changes due to temperature or exposure to light, or due to reactions with 
oxidants, metal ions, proteins or flavonoids, leading to changes in or loss of color (Rodriguez-Amaya, 2016). Anthocyanin stability can be increased by encapsulation (Zaidel et al., 2014).

Carotenoids are lipophilic colorants with yellow to red colors. The four major sources of beta carotene (E160a) are plants, algae, fungi and chemical synthesis (Mortensen, 2006).

Chlorophylls are the major photosynthetic pigments of plants, and are widely used as green food colorants, both in native and chemically modified forms (Humphrey, 2004).

The betalains, including betanin, are a class of natural pigments that occur in beetroot red (E162) (EFSA, 2015).

HPLC with UV/VIS or photodiode array detection (DAD) is the standard and most widely used analytical method for quantification of anthocyanins and beta carotene, due to its resolution, sensitivity and selectivity (Stintzing et al., 2006; Yoshioka and Ichihashi, 2008; Li et al., 2016; Su et al., 2016; Pedro et al., 2016). Simultaneous determination of mixtures of up to 40 colorants is feasible with HPLC-DAD, by scanning the eluate at suitably chosen wavelengths (Yoshioka and Ichihashi, 2008; Prado and Godoy, 2007; Minioti et al., 2007; Shen et al., 2014).

Besides HPLC, several alternative analytical methods are used for quantification, for example spectrophotometry (Sayar and Özdemir, 1998; Liang et al., 2011; Islam et al., 2016), capillary electrophoresis (Watanabe and Terabe, 2000), and colorimetry (Stintzing et al., 2006; Liang et al., 2011).

Optical methods like derivative spectrophotometry are generally not considered to be suitable for quantification in multi-color mixtures without mathematical processing of the data (Yoshioka and Ichihashi, 2008; Sayar and Özdemir, 1998).

Laser-based photoacoustic spectroscopy (LPAS) is a technique where a sample is illuminated with a monochromatic laser, with an intensity that is modulated at a fixed frequency. When the wavelength of the laser coincides with an absorption band of an analyte in the sample, the radiation absorbed by the sample is rapidly converted to heat (Dumitras et al., 2007). In the case of gaseous samples, the changes in pressure caused by this oscillating temperature change can be directly detected by a microphone, but in solid samples, the acoustic wave is generated within the solid sample, and propagates to the gaseous phase (Ball, 2006). Thermal waves also cause a periodic heating and cooling of the contacting layer of the surrounding gas. Both effects generate acoustic waves, which are detected by a microphone as a photoacoustic signal. The generated PA signal depends on optical and thermal parameters of the sample and the contacting gas.

The aim of this study was to explore the feasibility of laser-based photoacoustic spectroscopy (LPAS) and colorimetry for quantification of E163 and E160a in multiple colored hard-boiled candy samples, comparing the results with those achievable through colorimetry. A secondary target of the investigation was whether the effect of the two food colorants at the analytical wavelengths was independent.

\section{Materials and methods}

\subsection{Materials}

\subsubsection{Samples}

Ten solid hard-boiled candy calibration samples were used for colorimetry and LPAS measurements (Table 1). The samples were prepared according to a standard industrial process: corn syrup, granular sugar (sucrose), and water were cooked at atmospheric pressure to $143{ }^{\circ} \mathrm{C}$, after which further moisture was removed under reduced pressure (absolute pressure: 0.2 bar). The same amount of citric acid and flavor premix was added to each sample (titratable acidity calculated as citric acid: $0.26 \% \mathrm{~m} / \mathrm{m}$ ), and different amounts of colorants were added. The resulting candy mass was then mixed and cooled on a temperaturecontrolled table (temperature $20^{\circ} \mathrm{C}$ ), yielding a hard candy (in a glassy state of matter).

Two series of samples were prepared. Series A contains varying amounts of anthocyanin grape-extract (Chr. Hansen; AC 12 WSP, 
anthocyanin content $100 \%$ ) with no other color added. The anthocyanin content of these samples was 0.00 (blank sample), 5.06, 8.14, $10.65,14.75$ and $17.42 \mathrm{mg} / \mathrm{g}$. In series $\mathrm{B}$, two colorants were applied, namely the above mentioned grape extract and liquid beta carotene colorant (Naturex Natural carotene COOF3221; beta-carotene content $5 \%$ ). The amount of anthocyanin was fixed $(9.50 \pm 1.20 \mathrm{mg} / \mathrm{g})$, and the beta carotene contents were as follows: 0.00 (blank sample from beta carotene point of view), $0.16,0.22,0.37$ and $0.42 \mathrm{mg} / \mathrm{g}$.

Table 1. The ten investigated hard boiled candy samples and their colorant content. Series A means samples 5 to 10 and while series B samples 1-4 and 7.

\begin{tabular}{|l|l|l|}
\hline $\begin{array}{l}\text { Sample } \\
\text { number }\end{array}$ & $\begin{array}{l}\text { Anthocyanin } \\
\text { content } \\
\text { (mg/g) }\end{array}$ & $\begin{array}{l}\text { Beta carotene } \\
\text { content }(\mathbf{m g} / \mathbf{g})\end{array}$ \\
\hline 1 & 9.65 & 0.16 \\
\hline 2 & 9.06 & 0.22 \\
\hline 3 & 10.10 & 0.37 \\
\hline 4 & 8.42 & 0.42 \\
\hline 5 & 5.06 & 0.00 \\
\hline 6 & 8.14 & 0.00 \\
\hline 7 & 10.65 & 0.00 \\
\hline 8 & 14.75 & 0.00 \\
\hline 9 & 17.42 & 0.00 \\
\hline 10 & 0.00 & 0.00 \\
\hline
\end{tabular}

The samples for the LPAS measurement were crushed in a mortar to get relatively fine powders, and the colorimetric measurements were done with uncrushed as well as crushed (powdered) samples.

\subsection{Methods}

\subsubsection{Photoacoustic spectrophotometry}

The home-made PA spectrometer used in this study comprised a modulator, a photoacoustic cell and either a $473 \mathrm{~nm}$ diode laser (Changchun New Industries Optoelectronics, MBL-III-473-50) or a $532 \mathrm{~nm}$ diode laser (Roithner, GLP-III-532-30).

The laser beam was mechanically chopped at a frequency of $17 \mathrm{~Hz}$, collected by a quartz lens and focused into the PA cell. Radiation entered the PA cell through a quartz window $12.7 \mathrm{~mm}$ in diameter. A cylindrical polished stainless-steel sample holder chamber was used, with diameter $50 \mathrm{~mm}$ and height $20 \mathrm{~mm}$, with an engraved hemispherical hole for the samples on the top, $5 \mathrm{~mm}$ deep and $10 \mathrm{~mm}$ in diameter. The volume of sample required to fill the sample holder was approximately $0.15 \mathrm{~cm}^{3}$

A $3 \mathrm{~mm}$ long stainless-steel capillary tube with inner diameter $500 \mu \mathrm{m}$ was used to connect a $4.2 \times 4.75 \mathrm{~mm}$ electret microphone (Sennheiser KE 4-211-2) with the sample holder of the cell. The sensitivity of the microphone was $10 \mathrm{mV} / \mathrm{Pa}$ at $1000 \mathrm{~Hz}$. The PA signal was processed by a dual phase lock-in amplifier (Stanford SR530) with $3 \mathrm{~s}$ time constant coupled to the computer. To determine the PA signals three independent analyses were performed where each single measurement represents 256 successive readings of the lock-in signal, and the data points are the averages of three consecutive independent measurements.

\subsubsection{Colorimetry}

The colorimetric indices were measured by a MiniScan XE Plus (HunterLab) colorimeter with a CIE D65 xenon lamp as light source with a $45 / 0^{\circ}$ measurement geometry.

The results of colorimetry can be defined as direct CIELab (L*, a*, b*) and derived (Hue, $\left.\mathrm{C}^{*}, \Delta \mathrm{E}^{*}, 2-\lg \left(\mathrm{L}^{*}\right), \lg \left(\mathrm{a}^{*}+100\right), \lg \left(\mathrm{b}^{*}+100\right)\right)$ color indices respectively.

The $L^{*}$ index is the lightness value of the sample on the $0-100$ scale where 0 is black, and 100 is white. The $\mathrm{a}^{*}$ index expresses the position in the color space of a color on the green-red axis and $b^{*}$ on the blue-yellow axis. Negative $a^{*}$ is green and positive $\mathrm{a}^{*}$ is red while negative $\mathrm{b}^{*}$ is blue and positive $b^{*}$ is yellow.

Hue index $\left(\mathrm{h}_{\mathrm{ab}}{ }^{\circ}\right)$ is the rotational degree of a color vector from the positive $a^{*}$ axis in the CIELab color space. Chroma $\left(\mathrm{C}^{*}\right)$ is a quantitative attribute of colorfulness and used to determine the distance between a point in the color space and a grey color with the same lightness. The total color difference $\left(\Delta \mathrm{E}^{*}\right)$ represents the distance between two colors in the color space. We selected as reference point in the color space the $L^{*}=93.24, a^{*}=-0.82$ and 
$\mathrm{b}^{*}=0.07$ values which refer to the calibration white tile to the colorimeter.

CIELab indices of the candy samples (Series A and Series B) were measured, both crushed as in the sample preparation for the LPAS, and uncrushed. $L^{*}, a^{*}$ and $b^{*}$ indices were measured directly, whereas standard derived color indices $\left(\mathrm{C}^{*}\right.$, hue, $\left.\Delta \mathrm{E}^{*}\right)$ were calculated, and three new indices calculated $\left(2-\lg \left(\mathrm{L}^{*}\right), \quad \lg \left(\mathrm{a}^{*}+100\right)\right.$, $\lg \left(\mathrm{b}^{*+100)}\right)$.

Five independent measurements were performed on each sample, and the mean of the measured values was used. Statistical analysis was done with Microsoft Excel 2013.

\section{Results and discussions}

The PAS signals of the ten crushed candy samples, normalized to the output power of the lasers, are shown for series A (samples with only anthocyanin) and series B (sample with anthocyanin and beta carotene mixture) in Figure 1 and 2 respectively.

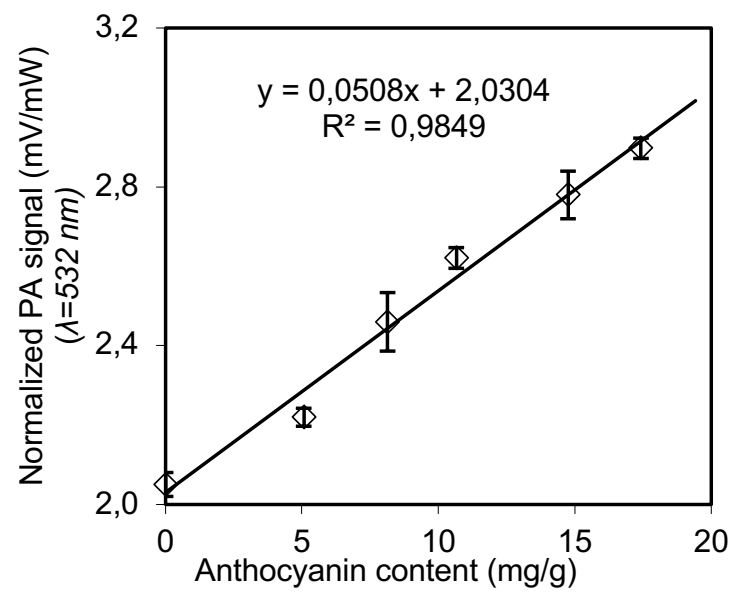

Figure 1. Calibration line between the anthocyanin content and the normalized PA signal measured on powdered, solid candy samples. The anthocyanin contents were between 0 and $17.42 \mathrm{mg} / \mathrm{g}$ and the samples do not contain $\beta$-carotene (mean $\pm \mathrm{SD}, \mathrm{n}=3$ ).

In both cases the normalized PA signal depends linearly on the color agent content of the samples, with good determination coefficients. Measuring the PA signal at $532 \mathrm{~nm}$ on the samples of series B (those containing anthocyanin) the obtained signal and the anthocyanin content do not differ significantly. This latter statement is confirmed by t-test $(\mathrm{p}<0.05)$ examined on the data.

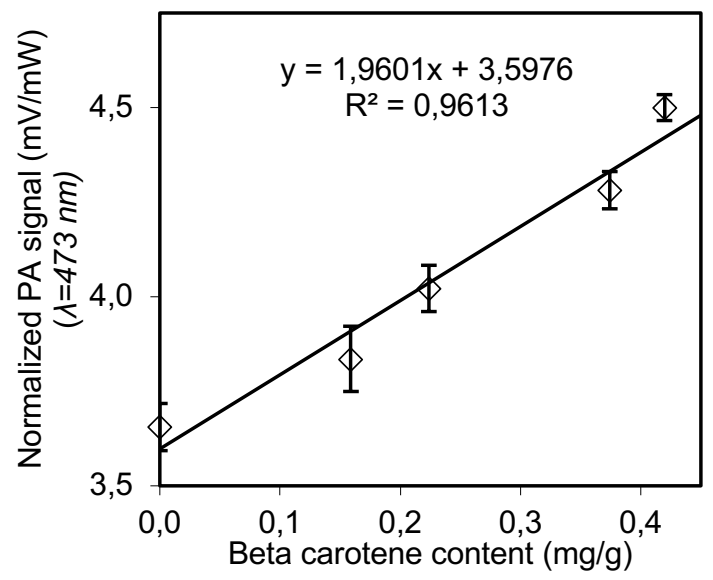

Figure 2. Calibration line between the beta carotene content and the normalized PA signal using the powdered, solid candy samples. The beta carotene contents were between 0 and 0.42 $\mathrm{mg} / \mathrm{g}$ while the anthocyanin content of the samples was $9.50 \pm 1.20 \mathrm{mg} / \mathrm{g}($ mean $\pm \mathrm{SD}, \mathrm{n}=3)$.

Table 2. The calculated results of the comparison on the basis of the determination coefficients between color indices and anthocyanin and beta carotene content. Values in the second and third column refer to samples series A (anthocyanin content only), while values in the fourth and fifth column refer to samples series B (beta carotene content with constant amount of anthocyanin). Five independent measurements were carried out on the uncrushed solid and crushed samples as well.

\begin{tabular}{|c|c|c|c|c|}
\hline \multirow{2}{*}{$\begin{array}{c}\text { Color } \\
\text { indices }\end{array}$} & \multicolumn{2}{|c|}{$\begin{array}{c}\text { Anthocyanin } \\
\text { content }\end{array}$} & \multicolumn{2}{c|}{$\begin{array}{c}\text { Beta carotene } \\
\text { content }\end{array}$} \\
\cline { 2 - 5 } & \multicolumn{2}{|c|}{$\mathrm{R}^{2}$} & \multicolumn{2}{c|}{$\mathrm{R}^{2}$} \\
\hline $\mathrm{L}^{*}$ & 0.8829 & $\mathbf{0 . 9 4 2 7}$ & 0.2242 & 0.2502 \\
\hline $\mathrm{a}^{*}$ & 0.5877 & 0.8396 & 0.3117 & 0.4591 \\
\hline $\mathrm{b}^{*}$ & 0.7101 & 0.8376 & $\mathbf{0 . 9 2 5 3}$ & $\mathbf{0 . 9 5 7 5}$ \\
\hline$\Delta \mathrm{E}^{*}$ & $\mathbf{0 . 9 9 6 7}$ & $\mathbf{0 . 9 5 0 7}$ & 0.1981 & 0.0106 \\
\hline Hue & 0.4048 & 0.3329 & $\mathbf{0 . 9 5 5 0}$ & $\mathbf{0 . 9 7 6 3}$ \\
\hline $\mathrm{C}^{*}$ & 0.2073 & 0.8780 & 0.3901 & 0.8114 \\
\hline $2-\lg \left(\mathrm{L}^{*}\right)$ & $\mathbf{0 . 9 4 2 6}$ & $\mathbf{0 . 9 4 9 7}$ & 0.2102 & 0.2502 \\
\hline $\lg \left(\mathrm{a}^{*}+100\right)$ & 0.5847 & 0.8321 & 0.3142 & 0.4594 \\
\hline $\lg \left(\mathrm{b}^{*}+100\right)$ & 0.7169 & 0.8427 & $\mathbf{0 . 9 2 8 9}$ & $\mathbf{0 . 9 6 1 0}$ \\
\hline
\end{tabular}


The second and third columns in Table 2 show the determination coefficients of linear regression for anthocyanin content (Series A). In the case of $\Delta \mathrm{E}^{*}$ for the uncrushed samples, the regression is not linear but quadratic. In uncrushed form the $2-\lg \left(\mathrm{L}^{*}\right)$ and $\Delta \mathrm{E}^{*}$ indices, while in powdered form the $\mathrm{L}^{*}, \Delta \mathrm{E}^{*}$, and 2$\lg \left(\mathrm{L}^{*}\right)$ indices show the best correlation.

As an example, Figure 3 shows the correlation between $\Delta \mathrm{E}^{*}$ index and the anthocyanin content for crushed and uncrushed samples. The quadratic regression gives better correlation $\left(\mathrm{R}^{2}=0.9967\right)$ but does not yield a monovalent function above $16,5 \mathrm{mg} / \mathrm{g}$ anthocyanin content. The measured $\mathrm{L}^{*}$ indices show that the crushing significantly darkens the samples. Values of $\mathrm{L}^{*}$ are $50-70 \%$ lower for crushed samples.

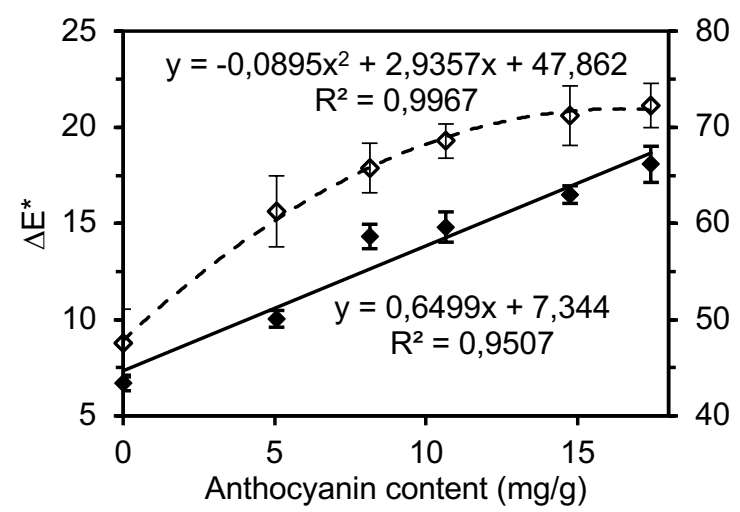

Figure 3. Calibration curves between $\Delta \mathrm{E}^{*}$ color indices and anthocyanin content for uncrushed $(\diamond)$ and crushed $(\diamond)$ samples series A (the samples contain anthocyanin only). The second $\mathrm{Y}$-axis belongs to the uncrushed samples. The values represent the average of five independent measurements and the standard deviations.

Determination coefficients for linear regression between colorimetric indices and beta carotene content (Series B) are shown also in Table 2 (fourth and fifth columns). The best correlation was achieved for parameter $b^{*}$, hue and $\lg \left(b^{*}+100\right)$ color indices, while the worst one was $\Delta \mathrm{E}^{*}$ in both forms. As an example, Figure 4 shows the correlation between hue index and beta carotene content for uncrushed and crushed samples. In both cases the correlation is linear with determination coefficients $\left(\mathrm{R}^{2}\right)$ of 0.955 and 0.9763 , respectively.

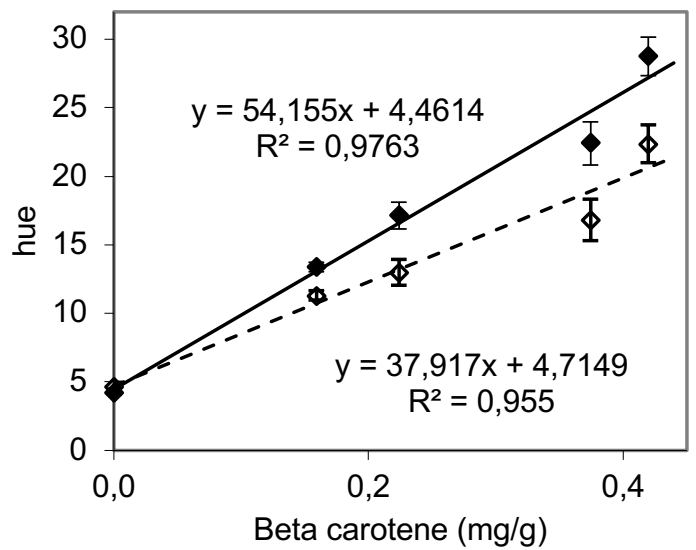

Figure 4. Calibration lines between hue indices and beta carotene content for uncrushed $(\diamond)$ and crushed $(\diamond)$ samples series B (the samples contain anthocyanin too). The values represent the average of five independent measurements and the standard deviations.

Comparison of the applied methods shows that anthocyanin and beta carotene content in hard boiled candy samples can be determined using both LPAS and colorimetry. A linear relationship was found between the colorant content and the PA signal in all cases, whereas this was only true for some of the CIELab indices. We consider only those correlations that have a determination coefficient higher than 0.9.

Accordingly, the anthocyanin content of the hard-boiled candy samples can be measured in uncrushed samples by colorimetry using the $\Delta \mathrm{E}^{*}$ and $2-\lg \left(\mathrm{L}^{*}\right)$ color indices, while in powdered form, $\mathrm{L}^{*}, \Delta \mathrm{E}^{*}$, and $2-\lg \left(\mathrm{L}^{*}\right)$ or by LPAS at $532 \mathrm{~nm}$.

The beta carotene colorant content of the uncrushed and powdered hard boiled candy samples can be determined by colorimetry using $\mathrm{b}^{*}$, hue, or $\lg \left(\mathrm{b}^{*}+100\right)$ color indices, or by LPAS at $473 \mathrm{~nm}$.

The best results from measurement of the anthocyanin colorant content in hard boiled candies with both anthocyanin and beta carotene were by LPAS at $532 \mathrm{~nm}$ and by colorimetry using $\Delta \mathrm{E}^{*}$. In both cases the determination 
coefficients were good for anthocyanin, while poor for beta carotene.

The beta carotene content in anthocyanin beta carotene colored candies potentially can be determined using the Hue colorimetrical index.

PA spectroscopy and colorimetry both offer some advantages compared with the conventional methods. No chemicals or special tools are required for preparation, and the whole analysis is significantly less time-consuming than with conventional methods. The results from LPAS require the same level of mathematical analysis as is needed in the interpretation of results from derivative spectrophotometry (Yoshioka and Ichihashi, 2008).

Although colorimeters are more widely available in industry, the results were shown to be less linear than those obtained with LPAS and were strongly affected by the physical condition of the sample.

\section{Conclusions}

The anthocyanin and beta carotene content in hard boiled candy samples can be determined using the applied methods: LPAS and colorimetry.

After validation of both methods, however, they could potentially be used as quality control methods to determine dosage of color agents in food supplement or confectionery production.

\section{References}

Ball, D.W. (2006). Photoacoustic spectroscopy. Spectroscopy, 21(9), 14-6.

Bateman, B., Warner, J.O., Hutchinson, E., Dean, T., Rowlandson, P., Gant, C., Grundy, J., Fitzgerald, C., Stevenson, J. (2004). The effects of a double blind, placebo controlled, artificial food colourings and benzoate preservative challenge on hyperactivity in a general population sample of preschool children. Archives of Disease in Childhoo., 89(6), 506-11.

Burrows, A.J.D. (2009). Palette of Our Palates: A Brief History of Food Coloring and Its Regulation. Comprehensive Reviews in Food Science and Food Safety, 8(4), 394-08.
Carocho, M., Morales, P., Ferreira, I.C.F.R. (2015). Natural food additives: Quo vadis? Trends in Food Science \& Technology, 45(2), 284-95.

Cassiday, L. (2017). Clean label: The next generation. INFORM International News on Fats, Oils, and Related Materials, 28(8), 610.

Cortez, R., Luna-Vital, D.A., Margulis, D., Mejla, E.G.D. (2017). Natural Pigments: Stabilization Methods of Anthocyanins for Food Applications. Comprehensive Reviews in Food Science and Food Safety 16(1), 18098.

Cui, B., Hu, Z., Zhang, Y., Hu, J., Yin, W., Feng, Y., Xie, Q., Chen, G. (2016). Anthocyanins and flavonols are responsible for purple color of Lablab purpureus (L.) sweet pods. Plant Physiology and Biochemistry, 103, 183-90.

Dumitras, D.C., Dutu, D.C., Matei, C., Magureanu, A.M., Petrus, M., Popa, C. (2007). Laser photoacoustic spectroscopy: principles, instrumentation, and characterization. Journal of Optoelectronics and Advanced Materials, 9(12), 3655-701.

EFSA ANS Panel (EFSA Panel on Food Additives and Nutrient Sources added to Food). (2015). Scientific Opinion on the reevaluation of beetroot red (E 162) as a food additive. EFSA Journal, 13(12), 4318.

Humphrey, A.M. (2004). Chlorophyll as a Color and Functional Ingredient. Journal of Food Science, 69(5), 422-5.

Islam, S.N., Nusrat, T., Begum, P., Ahsan, M. (2016). Carotenoids and b-carotene in orange fleshed sweet potato: A possible solution to vitamin A deficiency. Food Chemistry, 199, 628-1.

Li, D., Meng, X., Li, B. (2016). Profiling of anthocyanins from blueberries produced in China using HPLC-DAD-MS and exploratory analysis by principal component analysis. Journal of Food Composition and Analysis, 47, 1-7.

Liang, Z., Sang, M., Fan, P., Wu, B., Wang, L., Yang, S., Li, S. (2011). CIELAB Coordinates in Response to Berry Skin 
Anthocyanins and Their Composition in Vitis. Journal of Food Science, 76(3), 4907.

Mccann, D., Barrett, A., Cooper, C., Crumpler, D., Dalen, L., Grimshaw, K., Kitchin, E., Lok, K., Porteous, L., Prince, E., SonugaBarke, E., Warner, J.O., Stevenson, J. (2007). Food additives and hyperactive behaviour in 3-year-old and 8/9-year-old children in the community a randomized, double-blinded, placebo-controlled trial. The Lancet, 370(9598), 1560-7.

Minioti, K.S., Sakellariou, C.F., Nikolaos, S., Thomaidis, N.S. (2007). Determination of 13 synthetic food colorants in water-soluble foods by reversed-phase high-performance liquid chromatography coupled with diodearray detector. Analytica Chimica Acta, 583(1), 103-10.

Mortensen, A. (2006). Carotenoids and other pigments as natural colorants. Pure and Applied Chemistry, 78(8), 1477-91.

Pedro, A.C., Granato, D., Rosso, N.D. (2016). Extraction of anthocyanins and polyphenols from black rice (Oryza sativa L.) by modeling and assessing their reversibility and stability. Food Chemistry, 191, 12-20.

Prado, M.A., Godoy, H.T. (2007). Synthetic dyes are much used in processed foods. Quim Nova, 30(2), 268-73.

Prior, R.L., Wu, X. (2012). Analysis Methods of Anthocyanins In: Xu, Z., Howard, L.R. (Eds.) Analysis of Antioxidant-Rich Phytochemicals. Howard Wiley-Blackwell, 149.

Rakic, V.P., Skrt, M.A., Miljkovic, M.N., Kostic, D.A., Sokolovic, D.T., Ulrih, N.E.P. (2015). Effects of $\mathrm{pH}$ on the stability of cyanidin and cyanidin 3-O- $\beta$ glucopyranoside in aqueous solution. Hemijska industrija, 69(5), 511-22.

Rodriguez-Amaya, D.B. (2016). Natural food pigments and colorants. Current Opinion in Food Science, 7, 20-6.

Sayar, S., Özdemir, Y. (1998). First-derivative spectrophotometric determination of Ponceau 4R, Sunset Yellow and Tartrazine in confectionery products. Food Chemistry, 61(3), 367-2.

Shahid, M., Islam, S.U., Mohammad, F. (2013). Recent advancements in natural dye applications: a review. Journal of Cleaner Production, 53, 310-31.

Shen, Y., Zhang, X., Prinyawiwatkul, W., Xu, Z. (2014). Simultaneous determination of red and yellow artificial food colourants and carotenoid pigments in food products. Food Chemistry, 157, 553-8.

Sloan, A.E. (2011). Navigating the Natural Marketplace. Food Technology, 65(7), 24-3.

Stintzing, F.C., Trichterborn, J., Carle, R. (2006). Characterisation of anthocyaninbetalain mixtures for food colouring by chromatic and HPLC-DAD-MS analyses. Food Chemistry, 94(2), 296-09.

$\mathrm{Su}, \mathrm{X}$., Xu, J., Rhodes, D., Shen, Y., Song, W., Katz, B., Tomich, J., Wang, W. (2016). Identification and quantification of anthocyanins in transgenic purple tomato. Food Chemistry, 202, 184-8.

Torskangerpoll, K., Andersen, Ø.M. (2005). Colour stability of anthocyanins in aqueous solutions at various $\mathrm{pH}$ values. Food Chemistry, 89(3), 427-40.

Watanabe, T., Terabe, S. (2000). Analysis of natural food pigments by capillary electrophoresis. Journal of Chromatography A, 880(1-2), 311-22.

Wrolstad, R.E., Culver, C.A. 2012. Alternatives to Those Artificial FD\&C Food Colorants. Annual Review of Food Science and Technology, 3(1), 59-77.

Yoshioka, N., Ichihashi, K. (2008). Determination of 40 synthetic food colors in drinks and candies by high-performance liquid chromatography using a short column with photodiode array detection. Talanta, 74(5), 1408-13.

Zaidel, D.N.A., Sahat, N.S., Jusoh, Y.M.M., Muhamad, I.I. (2014). Encapsulation of Anthocyanin from Roselle and Red Cabbage for Stabilization of Water-in-Oil Emulsion. Agriculture and Agricultural Science Procedia, 2, 82-9. 